\title{
Comparison of PCDD/F levels and profiles in fly ash samples from multiple industrial thermal sources
}

\author{
Guorui Liu, Xiaoxu Jiang, Mei Wang, Shujun Dong, Minghui Zheng* \\ State Key Laboratory of Environmental Chemistry and Ecotoxicology, Research Center for Eco-Environmental Sciences, Chinese Academy of Sciences, P.O. Box 2871, Beijing \\ 100085, China
}

\section{H I G H L I G H T S}

- PCDD/F profiles in fly ash from 14 industrial sources were presented and compared.

- PCDD/F levels were highest in fly ash samples from secondary copper smelting.

- Source-specific ratios of PCDD/F congeners were suggested as diagnostic values.

- Equations describing correlations between congeners and PCDD/F TEQs were developed.

\section{A R T I C L E I N F O}

\section{Article history:}

Received 25 September 2014

Received in revised form 29 January 2015

Accepted 15 March 2015

Available online 27 April 2015

Handling Editor: Dr. H. Fiedler

\section{Keywords:}

Dioxins

Persistent organic pollutants

Profile

Fly ash

Industrial emission

\begin{abstract}
A B S T R A C T
A comprehensive comparison of the levels and profiles of polychlorinated dibenzo-p-dioxins and dibenzofurans (PCDD/F) in fly ash samples from multiple industrial sources may help to prioritize sources and to understand discrepancies in profiles. In this study, PCDD/F data from 113 fly ash samples from 14 sources reported in previous studies were summarized and compared. The highest PCDD/F levels occurred in samples from secondary copper smelting ( $\mathrm{SCu}$ ). Although PCDD/F levels from secondary zinc smelting (SZn) were slightly lower than those of SCu, the PCDD/F profiles varied widely between the two sources. For $\mathrm{SCu}$, more chlorinated homologs were dominant, with highest degrees of chlorination being 6.6 for PCDF and 7.2 for PCDD. For SZn, less chlorinated homologs were dominant, with lowest degrees of chlorination being 4.4 for PCDF and 4.8 for PCDD. We speculate that copper and zinc might promote PCDD/F formation by catalyzing different pathways of thermal reactions. Diagnostic ratios of specific $\mathrm{PCDD} / \mathrm{F}$ congeners for different sources were suggested to identify potential sources of PCDD/Fs in the environment. Equations describing correlations between congeners and PCDD/F toxic equivalents were established, which may be useful for rapid and inexpensive screening of the toxic levels of PCDD/Fs in fly ash samples.
\end{abstract}

(c) 2015 Elsevier Ltd. All rights reserved.

\section{Introduction}

Polychlorinated dibenzo-p-dioxins and dibenzofurans (PCDD/ Fs) pose potential risks to environmental and human health globally because of their toxicity, persistence, and long-range transport. Unintentional formation and emission from various industrial activities are the major sources of PCDD/Fs (Fiedler et al., 2000; Weber et al., 2008; Holt et al., 2010). Among industrial sources, waste incineration and metal smelting processes are widely recognized as the main sources of the formation and emission of PCDD/ Fs (Gullett et al., 2000; Aries et al., 2006; Ni et al., 2009; Ba et al., 2009b).

\footnotetext{
* Corresponding author. Tel.: +861062849172.

E-mail address: zhengmh@rcees.ac.cn (M. Zheng).
}

Solid residue and stack gas emissions are considered to be the most important release pathways of PCDD/Fs and other dioxin-like compounds from waste incineration and metal smelting processes (Fiedler, 2007; Liu et al., 2009, 2010, 2012, 2013, 2014). Heterogeneous reactions during thermal processes are the dominant formation mechanisms of PCDD/Fs (Takasuga et al., 2000). It is widely recognized that fly ash (a solid residue) can promote $\mathrm{PCDD} / \mathrm{F}$ formation by heterogeneous reactions during industrial thermal processes, as a result of the abundant carbonous residue and catalytic elements contained in fly ash (Tuppurainen et al., 2003; Chen et al., 2008; Altarawneh et al., 2009; Cobo et al., 2009). For stack gas emissions, air pollution control devices are normally installed in industrial plants for the purpose of removing contaminants from stack gas prior to emission to the atmosphere. Thus, reductions in emissions of dioxins might be achieved by the 
physical removal of fly ash particles containing PCDD/Fs (Chi et al., 2008). For example, although reductions in PCDD/F atmospheric emissions have been achieved through the removal of fly ash particles by dual bag filters (Chi et al., 2008), PCDD/Fs produced were actually not destroyed; this means that most of the produced PCDD/Fs were transferred into solid residues, including fly ash, by air pollution control devices. The treatment of solid residues containing PCDD/Fs remains a problem. Therefore, stack gas emissions of dioxins might accurately represent emissions into ambient air, while not accurately reflecting the formation levels and patterns of PCDD/Fs during industrial thermal processes. The PCDD/ $F$ levels and profiles of fly ash might be more representative than those of stack gas for studying the unintentional formation patterns of PCDD/Fs and underlying mechanisms.

A comprehensive and systematic evaluation and comparison of the PCDD/F levels and profiles from multiple industrial thermal sources may be helpful in prioritizing the sources, understanding their discrepancies in profiles, and identifying potential indicators of PCDD/F toxic equivalents (TEQs) (Fiedler et al., 2000; Grochowalski et al., 2007). Among numerous industrial thermal sources, waste incineration and metal smelting processes have been the main focus of PCDD/F emission studies (Yu et al., 2006; Gao et al., 2009; Ni et al., 2009; Ba et al., 2009b). Fiedler et al. (2000) evaluated PCDD/F patterns by statistically analyzing 109 stack gas samples from municipal solid waste incinerators, hazardous waste incinerators, and the iron and steel industries. Potential TEQ indicators of atmospheric PCDD/F emissions have also been identified by the statistical analysis of stack gas emissions samples (Fiedler et al., 2000; Gullett and Wikström, 2000; Oh et al., 2004; Jansson and Andersson, 2012). Fly ash, a solid residue, is an important pathway for the release of PCDD/F and is the most important catalytic matrix for the promotion of $\mathrm{PCDD} / \mathrm{F}$ formation by heterogeneous reactions. However, a comprehensive and systematic evaluation and comparison of the PCDD/F levels and profiles of fly ash samples from multiple industrial thermal processes is still lacking.

Previous studies have reported on PCDD/F concentrations and profiles of fly ash samples from coking processes (Liu et al., 2013), primary magnesium smelting processes (Nie et al., 2011), primary copper smelting processes, (Nie et al., 2012a) and secondary copper, aluminum, zinc, and lead smelting processes (Ba et al., 2009a,b; Nie et al., 2012b), and iron and steel making (Lv et al., 2011a,b). In this study, data from studies on the PCDD/F levels and profiles of fly ash were summarized and compared (Ba et al., 2009a,b; Nie et al., 2011, 2012a,b; Lv et al., 2011a,b, 2013); and PCDD/F data from 113 fly ash samples from 14 types of industrial thermal sources were systematically evaluated and compared. To the best of our knowledge, this is the most comprehensive and systematic analysis of PCDD/F levels and profiles in fly ash sample from multiple industrial thermal sources in China. The primary aims of this study were: (1) to compare the formation levels of PCDD/Fs from multiple industrial sources, which could help understand the priority sources of PCDD/F formation, and to implement control activities for inhibiting PCDD/F formation; (2) to obtain a comprehensive evaluation of the differences in homolog distributions and congener profiles of PCDD/Fs from multiple industrial thermal sources, which might enhance the understanding of PCDD/F patterns and potential mechanisms involved; (3) to assess the correlations between specific congeners and PCDD/F TEQs in the solid residue phase, which could help identify the potential marker congeners of PCDD/F formation in solid residues that occur industrial thermal processes.

\section{Materials and methods}

\subsection{Information on the fly ash samples}

We have previously reported on several studies of dioxin concentrations, profiles, and emission factors in fly ash samples from coking processes (Liu et al., 2013), primary magnesium smelting (Nie et al., 2011), primary copper smelting processes (Nie et al., 2012a) and secondary copper, aluminum, zinc and lead smelting processes (Ba et al., 2009a,b; Nie et al., 2012b), and iron and steel making (Ba et al., 2009a,b; Lv et al., 2011a,b). In those studies, fly ash samples produced during different incineration or metal smelting stages were collected from the dust arrestors (bag fabric filters, electrostatic precipitator, and cyclones). In this study, the PCDD/F levels and profiles in fly ash samples from municipal solid waste incineration, hazardous waste incineration, iron ore sintering, and converter steel-making were determined. Data on the PCDD/ F levels and profiles in fly ash from previous studies were also summarized and included for comparison. PCDD/F data from 113 fly ash samples obtained from 14 types of industrial thermal source in China were collected and evaluated. Basic information on the source categories and fly ash samples is presented in Table 1.

\subsection{Chemical analysis, quality assurance, and quality control}

PCDD/Fs were analyzed by isotope dilution high resolution gas chromatography-high resolution mass spectrometry (HRGC/ HRMS) according to US Environmental Protection Agency (EPA) method 8290. Details of the sample extraction, cleanup, and instrumental analysis procedures for the PCDD/Fs have been described in detail in our previous studies (Ba et al., 2009b; Liu et al., 2013). Briefly, the fly ash samples were spiked with known amounts of ${ }^{13} \mathrm{C}_{12}$-labeled PCDD/Fs, treated with $1 \mathrm{~mol} \mathrm{~L}^{-1} \mathrm{HCl}$, then Soxhlet

Table 1

Basic information on the source categories and fly ash samples.

\begin{tabular}{|c|c|c|c|c|}
\hline Source category & Abbreviation & APCD & Number of samples & Ref. \\
\hline Municipal solid waste incineration & MSWI & Bag filter & 14 & - \\
\hline Hazardous waste incineration & HWI & Bag filter & 11 & - \\
\hline Thermal wire reclamation & TWR & Bag filter & 3 & (Nie et al., 2012b) \\
\hline Converter furnace for steel-making & CVF & Bag filter & 4 & - \\
\hline Iron ore sintering & IOS & Electrostatic precipitator or cyclones & 4 & - \\
\hline Iron foundry & IC & Bag filter & 14 & (Lv et al., 2011a) \\
\hline Coking processes & $\mathrm{CP}$ & Bag filter & 16 & (Liu et al., 2013) \\
\hline Secondary copper smelting & $\mathrm{SCu}$ & Bag filter & 14 & (Ba et al., 2009b; Nie et al., 2012a) \\
\hline Secondary aluminum smelting & SAl & Bag filter & 13 & (Ba et al., 2009b) \\
\hline Secondary zinc smelting & SZn & Bag filter & 2 & (Ba et al., 2009a) \\
\hline Secondary lead smelting & $\mathrm{SPb}$ & Bag filter & 2 & (Ba et al., 2009a) \\
\hline Primary copper smelting & $\mathrm{PCu}$ & Bag filter & 2 & (Nie et al., 2012a) \\
\hline Primary magnesium smelting & PMg & Bag filter & 5 & (Nie et al., 2011) \\
\hline Hot dip galvanizing & HDG & Diffuse ash & 9 & (Lv et al., 2011b) \\
\hline
\end{tabular}


extracted with $250 \mathrm{~mL}$ of toluene for $24 \mathrm{~h}$. The extracts were concentrated in a rotary evaporator, then subjected to a series of cleanup steps, including columns containing silica gel treated with $44 \%$ (by weight) $\mathrm{H}_{2} \mathrm{SO}_{4}$ and multilayer silica gel columns and basic alumina columns. The eluate was reduced to about $20 \mu \mathrm{L}$ by rotary evaporation under a gentle stream of nitrogen, and ${ }^{13} \mathrm{C}_{12}$-labeled PCDD/F standards were added.

The PCDD/Fs congeners were identified and quantified using an HRGC/HRMS instrument, which monitored two ions for each analyte. Separation was achieved using a DB-5 ms fused silica column (60 $\mathrm{m}$ long, $0.25 \mathrm{~mm}$ i.d., $0.25 \mu \mathrm{m}$ film thickness). The HRMS instrument was operated at around 10000 resolutions in selected ion monitoring mode.

To identify the PCDD/F congeners, retention time had to be within $2 \mathrm{~s}$ of the retention time of the equivalent ${ }^{13} \mathrm{C}_{12}$-labeled internal standard, and the ratio of the two monitored ions for the analyte had to be within $15 \%$ of the theoretical value. The recoveries for the ${ }^{13} \mathrm{C}_{12}$-labeled internal PCDD/Fs had to meet the requirements of US EPA method 8290. Laboratory method blank samples were included in each sample batch analyzed; octachlorodibenzop-dioxin (OCDD) and octachlorodibenzofuran (OCDF) were found in the blanks at concentrations above their LODs, but concentrations were equivalent to less than $10 \%$ of the concentrations present in fly ash samples.

\subsection{Method used for identifying potential indicator congeners of $P C D D / F T E Q$ in fly ash}

We used linear regression analysis to explore the correlations between congener and PCDD/F TEQs. The general regression equation is shown in Eq. (1). Excel 2013 software was used for the linear fitting.

$\mathrm{PCDD} / \mathrm{F} \mathrm{TEQ}=a \times($ congener concentration $)+b$

To evaluate the similarities and differences in congener profiles and homolog distributions, and to minimize the influence of total concentrations of PCDD/Fs, the homolog and congener concentrations were normalized to $\sum \mathrm{PCDD} / \mathrm{F}$ and $\sum 2378-\mathrm{PCDD} / \mathrm{F}$, respectively.

\section{Results and discussion}

\subsection{Comparison of PCDD/F concentrations and TEQs in fly ash samples from multiple industrial thermal sources}

Heterogeneous reactions on the fly ash surface are widely recognized as the most important pathway for the unintentional formation of PCDD/Fs; this is a more important pathway than gas phase formations of PCDD/Fs at high temperatures (Tuppurainen et al., 1998). Thus, the PCDD/F concentrations in fly ash might accurately represent the formation levels of PCDD/Fs during industrial thermal processes. Comparing the PCDD/F levels in fly ash from multiple industrial thermal sources might be helpful for prioritizing $\mathrm{PCDD} / \mathrm{F}$ formation sources and implementing control activities. The comparison of mass concentrations of 2378-PCDD/ $\mathrm{F}$ and TEQs in fly ash samples from 14 industrial sources are presented in Fig. 1. The highest concentrations and TEQs of PCDD/Fs were observed in fly ash samples from secondary copper smelting processes, followed by secondary zinc smelting, secondary aluminum smelting, and hazardous waste incineration processes. The PCDD/F concentrations and TEQs in fly ash samples collected from iron ore sintering and thermal wire reclamation were comparable, and were slightly higher than that of municipal solid waste incineration. The concentrations and TEQs of PCDD/Fs from
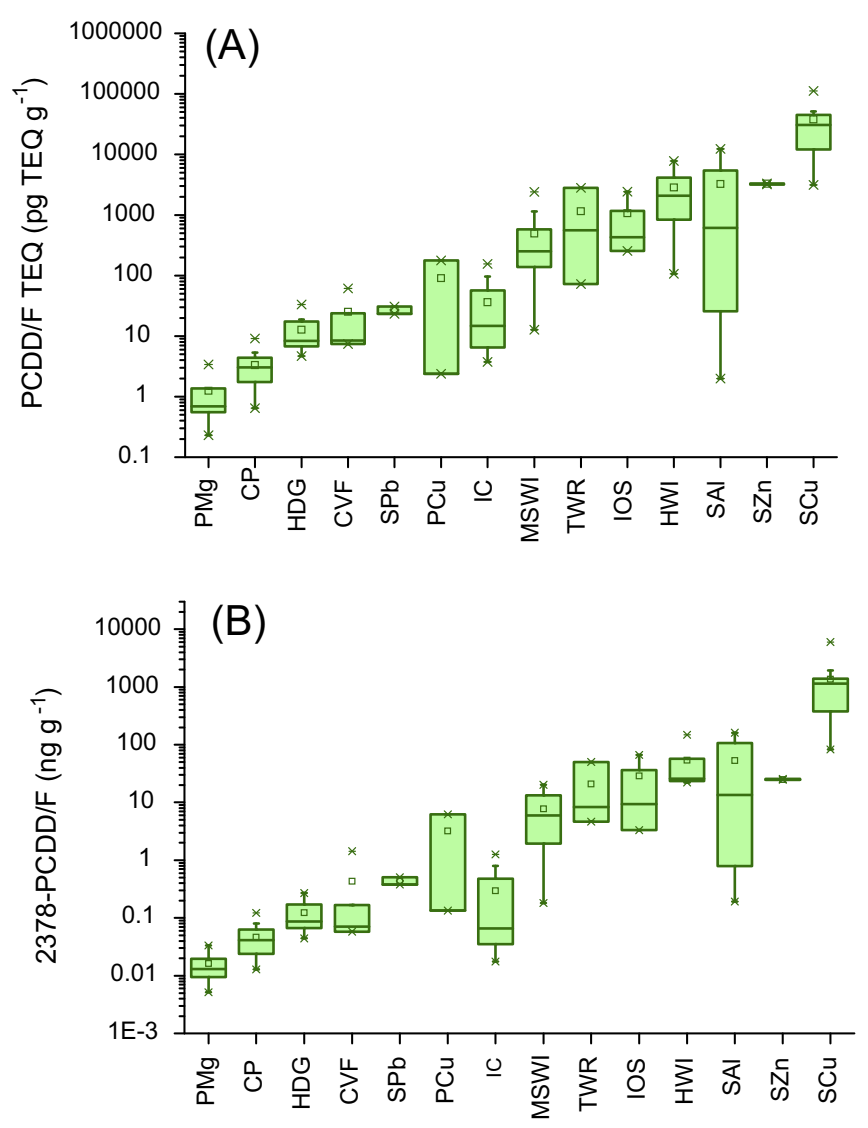

Fig. 1. Comparison of PCDD/F TEQs (A), and 2378-PCDD/F concentrations (B) in fly ash from 14 industrial thermal sources.

primary magnesium smelting and coking processes were relatively low. Generally, PCDD/F TEQs in fly ash samples from seven industrial sources (secondary copper, zinc, aluminum smelting and hazardous waste incineration, iron ore sintering, thermal wire reclamation, and municipal solid waste incineration) were higher than $100 \mathrm{pg}^{\mathrm{TEQ}} \mathrm{g}^{-1}$. For the other seven industrial sources, the PCDD/F TEQs of fly ash samples were lower than $100 \mathrm{pg} \mathrm{TEQ}^{-1}$. As seen in Fig. 1, the trends of 2378-PCDD/F concentrations of different sources were in good agreement with those of PCDD/F TEQs. Generally, the PCDD/F concentrations and TEQs of fly ash samples from secondary nonferrous smelting processes and hazardous waste incineration were higher than from municipal solid waste incineration, primary nonferrous smelting processes, and iron, and steel making processes.

To minimize PCDD/F formation and emissions, the development and application of best available technology/best environmental practices (BAT/BEP) for priority sources are encouraged. Guidelines on BAT/BEP for unintentional POPs have been developed by an expert group under the Stockholm Convention on Persistent Organic Pollutants (POPs) (Richter and Steinhauser, 2003; Fiedler, 2007; UNEP, 2014). For some industrial sources with high formation potential and high emission intensities, there would be greater reduction opportunity if BAT/BEP were applied to those sources. The comparison of PCDD/F levels of fly ash samples from 14 industrial thermal sources suggests that there might be much higher reduction opportunity in PCDD/F formation from secondary copper, aluminum, zinc smelting processes, hazardous waste incineration, and iron ore sintering process, considering that the release intensities are higher in solid residues than other sources. 
3.2. Homolog distributions and congener profiles of PCDD/Fs in fly ash from multiple industrial thermal sources

To compare the homolog distributions of PCDD/Fs of fly ash from 14 different sources, the homolog concentrations were normalized to the $\sum \mathrm{PCDD} / \mathrm{F}$ with the aim of minimizing the influence of concentrations. The homolog distributions of PCDD/Fs in fly ash from 14 sources are shown in Fig. 2. As expected differences in the homolog distributions of PCDD/Fs between 14 different industrial thermal sources were observed. For secondary copper smelting processes, the fractions of both PCDD and PCDF homologs successively increased as the number of chlorines increased. The conversely homolog trends of PCDD and PCDF homologs successively decreased as the number of chlorines increased were observed for secondary zinc and lead smelting processes. For secondary aluminum smelting processes, variations in the fractions of different PCDD and PCDF homologs were not large, and hexaCDF and hexaCDD were the most dominant homologs of PCDF and PCDD, respectively. HexaCDF and hexaCDD were also the most dominant homologs of PCDF and PCDD, respectively, for iron ore sintering processes. For municipal solid waste incineration, converter steel-making, and coking processes, successive decreases in the number of chlorines were observed for PCDF homologs, while the variations in PCDD homologs were not obvious.

Fig. 3 shows the average chlorination degrees of PCDDs and PCDFs from 14 industrial thermal sources. Generally, the chlorination degrees of PCDD were slightly higher than those of PCDFs. The highest chlorination degrees for both PCDD and PCDF were found in secondary copper smelting sources. The chlorination degrees of PCDD and PCDF were relatively high, with a value higher than 6.0 for secondary and primary copper, and secondary aluminum smelting, thermal wire reclamation, and iron ore sintering sources. The chlorination degrees of PCDD and PCDF for secondary zinc smelting processes were lowest, with values around 4.5 , followed by secondary lead smelting processes.

Among four secondary nonferrous smelting processes, the homolog fractions of secondary copper and aluminum smelting processes were contrary to those of secondary zinc and lead smelting processes. For example, the fractions of tetraCDF were very low for secondary copper and aluminum smelting processes, while they were the highest for secondary zinc and lead smelting processes. The fractions of heptaCDF, OCDF, and OCDD of secondary copper and aluminum processes were higher than those of

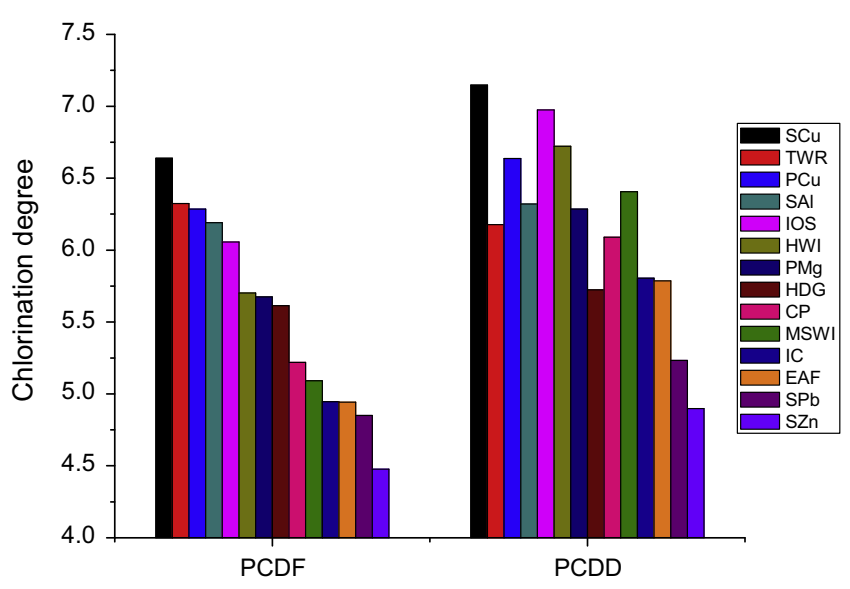

Fig. 3. The average chlorination degree of PCDF and PCDD in fly ash from 14 industrial thermal sources.

secondary zinc and aluminum processes. The homolog distributions are normally correlated with the potential formation mechanism of PCDD/Fs. The different homolog distributions suggest different formation mechanisms of PCDD/Fs between different secondary nonferrous smelting processes. We speculate that, based on the homolog distributions, copper might promote the formation of higher chlorinated homologs, while zinc and lead may lead to the formations of lower chlorinated homologs.

Congener concentrations were normalized to $\sum 2378-\mathrm{PCDD} / \mathrm{F}$ with the aim of minimizing the influence of concentrations. The profiles of 17 2378-substitued congeners are presented in Fig. 4. As seen in Fig. 4, the fractions of $1234789-\mathrm{HpCDF}$ and all the hexa-chlorinated furan congeners, which include 123478-HxCDF, 123678-HxCDF, 234678-HxCDF, and 123789-HxCDF, were very similar between the 14 different sources. The fractions of hexachlorinated dioxin congeners were also similar. Conversely, the fractions of tetra-, penta-, and octa-chlorinated dioxin and furan congeners varied widely between the 14 different industrial sources. For example, the fractions of OCDF were below 0.05 for municipal solid waste incineration and iron foundry sources; in the range of $0.05-0.1$ for hazardous waste incineration, iron ore sintering, converter furnaces for steel making, and secondary zinc smelting; in the range of $0.1-0.15$ for coking process and hot dip

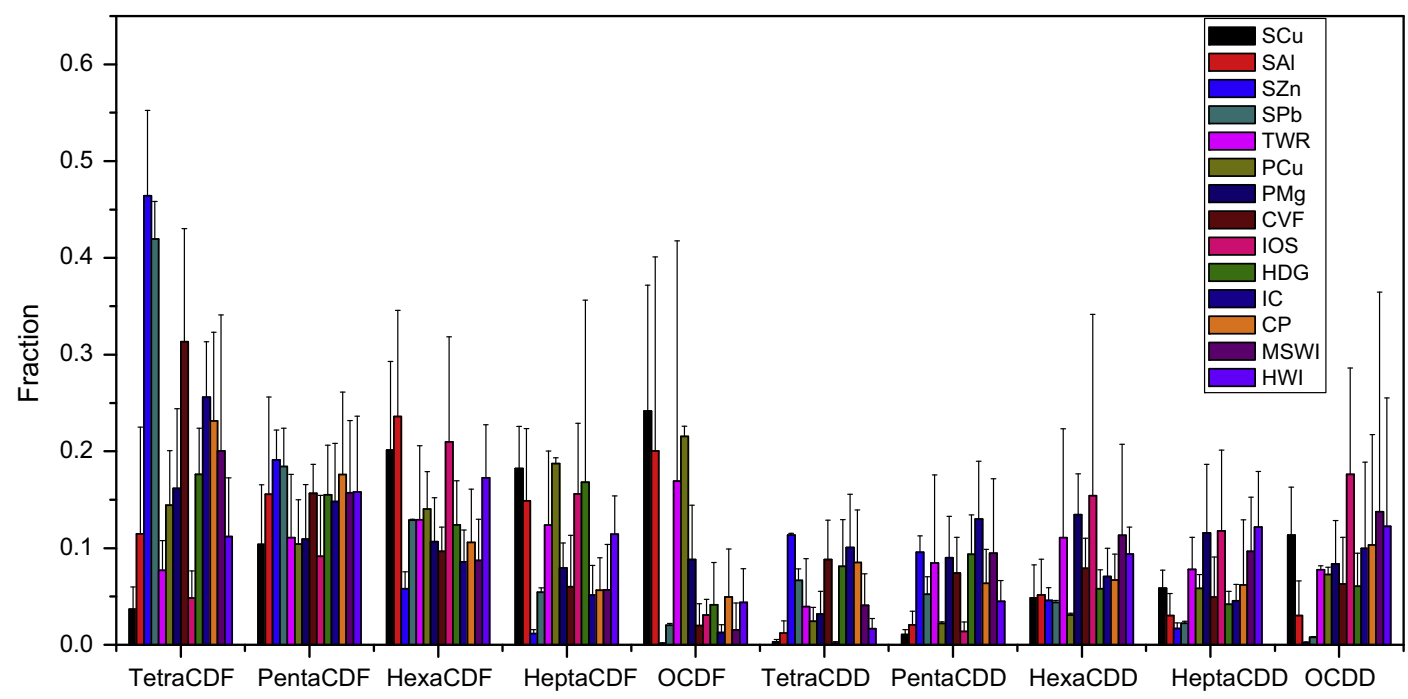

Fig. 2. Homolog distributions normalized to sum of PCDD/F in fly ash from 14 industrial thermal sources. 


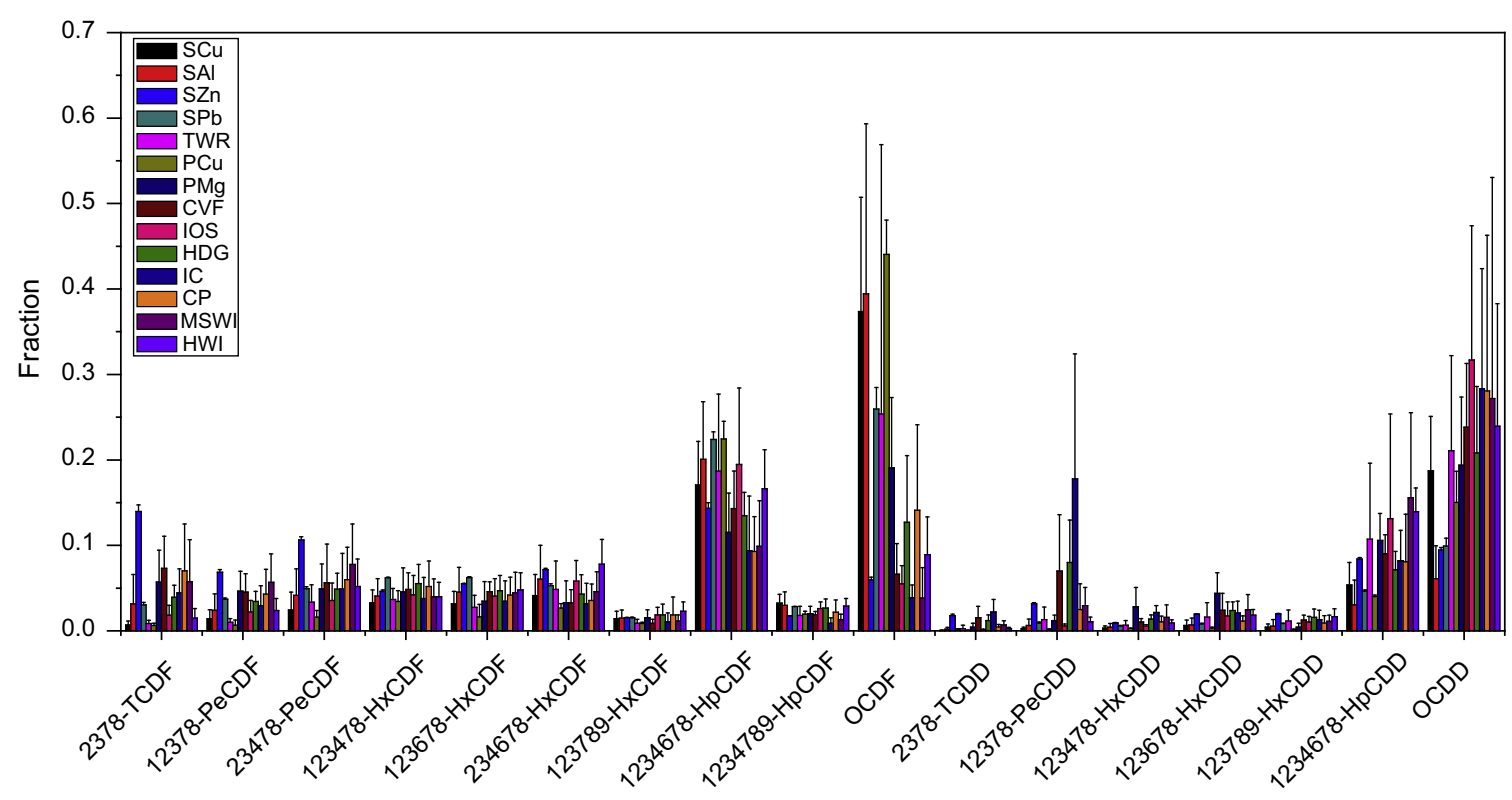

Fig. 4. Congener profiles of PCDD/Fs in fly ash from 14 industrial thermal sources.

galvanizing, in the range of $0.15-0.2$ for primary magnesium smelting; in the range of $0.2-0.3$ for secondary lead smelting and thermal wire reclamation; and were greater than 0.3 for secondary copper and aluminum smelting, and primary copper smelting processes. The clear differences in congener fractions might provide specific information for differentiating the 14 different sources. To further magnify the discrepancies and evaluate the differences in congener profiles of 14 industrial thermal sources, the ratios of the congeners with obviously different fractions were calculated and are shown in Table 2. The geometric means of ratios of specific congeners ranged from 0.4 to 479 , covering nearly three orders of magnitudes. The ratios that vary to a large extent for different sources might provide diagnostic values for establishing predictive models to identify the specific sources and quantify their contribution to $\mathrm{PCDD} / \mathrm{F}$ contamination in environmental matrices.

\subsection{Assessment of the correlations between specific congeners and PCDD/F TEQs in fly ash}

Some studies have been conducted to identify indicator compounds for fast and less costly predictions of PCDD/F TEQs (Fiedler et al., 2000; Oh et al., 2004; Pandelova et al., 2006). However, there is still no agreement on which is the most suitable TEQ indicator. Specific 2,3,7,8-substituted PCDD/F congeners, such as 2,3,4,7,8-pentachlorodibenzofuran, lower chlorinated homologs, including mono to tri- $\mathrm{CDD} / \mathrm{F}$, chlorobenzes, and chlorophenols, have been suggested in different publications (Gullett and Wikström, 2000; Blumenstock et al., 2001; Tsuruga et al., 2007). Stack gas emissions were the main focus of studies examining the potential indicators of PCDD/F TEQs in atmospheric emissions. To our knowledge, the identification of potential marker congeners for PCDD/F TEQs in solid residues from industrial thermal sources based on a large sample size have not been intensively reported. In this study, the correlations of 17 2,3,7,8-substituted congeners with PCDD/F TEQs in 113 fly ash samples were examined by linear regression analysis. The results presented in Table 3 show that most of the 2,3,7,8-substituted congeners (11 among 17 congeners) correlated significantly with PCDD/F TEQs, with correlation coefficients $\left(R^{2}\right)$ above 0.83 , which were not significantly affected by industrial source types, raw materials, or techniques. The correlations of six higher chlorinated congeners, including OCDF, 1234789-HpCDF, 234678-HxCDF, 1234678-HpCDF, OCDD, and 123789-HxCDD with PCDD/F TEQs were relatively low, with $R^{2}$ in the range of $0.6-0.8$.

A study by $\mathrm{Oh}$ et al. showed that correlations between higher chlorinated homologs (including OCDD and OCDF) and PCDD/F TEQs were higher than those between lower chlorinated homologs (tetraCDD, pentaCDD, tetraCDF, etc) and PCDD/F TEQs in stack gas emission during waste incineration (Oh et al., 2004). However, our results indicated that correlations between lower chlorinated

Table 2

Ratios of several specific PCDD/F congeners in fly ash from 14 industrial thermal sources.

\begin{tabular}{|c|c|c|c|c|c|c|c|c|c|c|c|c|c|c|c|}
\hline Ratios & & $\mathrm{SCu}$ & SAl & SZn & $\mathrm{SPb}$ & TWR & $\mathrm{PCu}$ & PMg & CVF & IOS & HDG & IC & $\mathrm{CP}$ & MSWI & HWI \\
\hline \multirow[t]{2}{*}{ OCDF to $2378-\mathrm{TCDF}$} & Geomean & 62 & 18 & 0.43 & 9 & 17 & 73 & 4 & 1 & 3 & 3 & 1 & 2 & 1 & 7 \\
\hline & Median & 61 & 17 & 0.43 & 9 & 9 & 77 & 2 & 1 & 2 & 3 & 1 & 2 & 1 & 9 \\
\hline \multirow[t]{2}{*}{ OCDF to $12378-\mathrm{PeCDF}$} & Geomean & 30 & 19 & 0.87 & 7 & 15 & 89 & 4 & 1 & 3 & 3 & 2 & 3 & 1 & 5 \\
\hline & Median & 32 & 29 & 0.87 & 7 & 9 & 123 & 4 & 2 & 2 & 4 & 2 & 2 & 1 & 5 \\
\hline \multirow[t]{2}{*}{ OCDD to $2378-T C D D$} & Geomean & 479 & 42 & 5 & 44 & 202 & 295 & 23 & 23 & 310 & 15 & 15 & 65 & 41 & 105 \\
\hline & Median & 354 & 20 & 5 & 45 & 354 & 303 & 27 & 18 & 432 & 12 & 14 & 67 & 24 & 106 \\
\hline \multirow[t]{2}{*}{ OCDD to $12378-\mathrm{PeCDD}$} & Geomean & 84 & 13 & 3 & 11 & 29 & 86 & 17 & 6 & 51 & 3 & 2 & 14 & 10 & 25 \\
\hline & Median & 74 & 7 & 3 & 11 & 21 & 86 & 24 & 3 & 72 & 2 & 2 & 15 & 6 & 22 \\
\hline \multirow{2}{*}{$1234678-\mathrm{HpCDD}$ to $2378-\mathrm{TCDD}$} & Geomean & 129 & 20 & 5 & 21 & 82 & 80 & 13 & 9 & 104 & 5 & 4 & 20 & 27 & 64 \\
\hline & Median & 107 & 22 & 5 & 21 & 110 & 88 & 13 & 7 & 221 & 6 & 3 & 16 & 28 & 69 \\
\hline \multirow[t]{2}{*}{$1234678-\mathrm{HpCDD}$ to $12378-\mathrm{PeCDD}$} & Geomean & 23 & 6 & 3 & 5 & 12 & 23 & 9 & 2 & 17 & 1 & 1 & 4 & 6 & 15 \\
\hline & Median & 22 & 5 & 3 & 5 & 11 & 24 & 13 & 1 & 20 & 1 & 0.45 & 3 & 6 & 16 \\
\hline
\end{tabular}


Table 3

Equations describing the relationships between potential indicator congeners and PCDD/F TEQs in fly ash $(n=113, p<0.05) y=a \times x+b$.

\begin{tabular}{llcrl}
\hline$y$ & $x$ & $a$ & \multicolumn{1}{l}{$b$} & $R^{2}$ \\
\hline PCDD/F TEQ & 2378-TCDF & 3.20 & 656 & 0.84 \\
PCDD/F TEQ & 12378-PeCDF & 1.67 & 1024 & 0.89 \\
PCDD/F TEQ & $23478-P e C D F$ & 1.12 & 722 & 0.96 \\
PCDD/F TEQ & $123478-H x C D F$ & 0.83 & 799 & 0.87 \\
PCDD/F TEQ & $123678-H x C D F$ & 0.87 & 601 & 0.92 \\
PCDD/F TEQ & 234678-HxCDF & 0.78 & 1016 & 0.60 \\
PCDD/F TEQ & $123789-H x C D F$ & 2.28 & 207 & 0.93 \\
PCDD/F TEQ & $1234678-H p C D F$ & 0.17 & 1056 & 0.72 \\
PCDD/F TEQ & $1234789-H p C D F$ & 0.84 & 815 & 0.78 \\
PCDD/F TEQ & OCDF & 0.035 & 2819 & 0.58 \\
PCDD/F TEQ & 2378-TCDD & 51.13 & 458 & 0.86 \\
PCDD/F TEQ & $12378-P e C D D$ & 10.15 & 37 & 0.93 \\
PCDD/F TEQ & $123478-H x C D D$ & 9.62 & 133 & 0.96 \\
PCDD/F TEQ & $123678-H x C D D$ & 4.48 & 755 & 0.83 \\
PCDD/F TEQ & $123789-H x C D D$ & 6.4 & 940 & 0.66 \\
PCDD/F TEQ & $1234678-H p C D D$ & 0.54 & 417 & 0.89 \\
PCDD/F TEQ & OCDD & 0.123 & 1480 & 0.70 \\
\hline
\end{tabular}

congeners (tetra- or penta-) and PCDD/F TEQs were generally higher than those between higher chlorinated congeners and PCDD/F TEQs in fly ash samples from multiple industrial sources. Generally, there may be differences in the TEQ indicators for stack gas and solid residue phases. The PCDD/F TEQ indicators identified by stack gas samples might accurately represent the atmospheric emission levels, but may not accurately reflect the formation levels of PCDD/Fs, considering the influence of physical removal and transfer of PCDD/Fs into solid residues by air pollution control devices. Heterogeneous reactions on fly ash during industrial thermal processes are widely recognized as the dominant formation mechanisms of PCDD/Fs. Therefore, we suggest that the marker congeners identified by fly ash samples might be better representatives of PCDD/F formation levels than those of stack gas indicators, which may be used as the indicators of PCDD/F formation intensity for specific industrial sources. Further research is needed to clarify the underlying factors contributing to the observed discrepancy in correlations between specific congeners and PCDD/F TEQs in the stack gas emission phase and the solid residue phase.

Equations describing the relationships between congeners and PCDD/F TEQs are useful for rapid and inexpensive predictions of PCDD/F TEQs in solid residues from multiple industrial sources through the measurement of the indicator congeners. In this study, equations describing the relationships between indicator congeners and PCDD/F TEQs were established by linear regression analysis and presented in Table 3. Those equations are useful for fast and less costly screening the toxic levels of PCDD/Fs in numerous fly ash samples from various industrial thermal sources by only determination of single congener.

\section{Conclusions}

We systematically evaluated the levels and profiles of PCDD/Fs in 113 fly ash samples from 14 industrial thermal sources. The comparison in PCDD/F levels from fourteen industrial sources suggested that secondary copper smelting industry might be the priority source for developing inhibiting technique to reduce the PCDD/ F formation during smelting processes. PCDD/F TEQs of most of the fly ash samples from seven industrial sources, including secondary copper, zinc, and aluminum smelting, hazardous waste incineration, iron ore sintering, thermal wire reclamation, and municipal

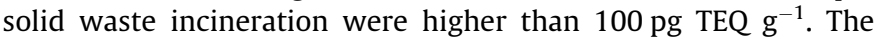
established equations describing the relationships between potential indicator congeners and PCDD/F TEQs in fly ash are helpful for fast and less costly screening the toxic levels of PCDD/Fs in numerous fly ash samples by only determination of single congener.

\section{Acknowledgments}

We gratefully acknowledge support from the National 973 program (2015CB453100), National Natural Science Foundation of China (21477147).

\section{References}

Altarawneh, M., Dlugogorski, B., Kennedy, E., Mackie, J., 2009. Mechanisms for formation, chlorination, dechlorination and destruction of polychlorinated dibenzo-p-dioxins and dibenzofurans (PCDD/Fs). Prog. Energy Combust. Sci. $35,245-274$.

Aries, E., Anderson, D.R., Fisher, R., Fray, T.A.T., Hemfrey, D., 2006. PCDD/F and "dioxin-like" PCB emissions from iron ore sintering plants in the UK. Chemosphere 65, 1470-1480.

Ba, T., Zheng, M.H., Zhang, B., Liu, W.B., Su, G.J., Xiao, K., 2009a. Estimation and characterization of PCDD/Fs and dioxin-like PCB emission from secondary zinc and lead metallurgies in China. J. Environ. Monit. 11, 867-872.

Ba, T., Zheng, M.H., Zhang, B., Liu, W.B., Xiao, K., Zhang, L.F., 2009b. Estimation and characterization of PCDD/Fs and dioxin-like PCBs from secondary copper and aluminum metallurgies in China. Chemosphere 75, 1173-1178.

Blumenstock, M., Zimmermann, R., Schramm, K.W., Kettrup, A., 2001. Identification of surrogate compounds for the emission of PCDD/F (I-TEQ value) and evaluation of their on-line realtime detectability in flue gases of waste incineration plants by REMPI-TOFMS mass spectrometry. Chemosphere 42, 507-518.

Chen, T., Yan, J.H., Lu, S.Y., Li, X.D., Gu, Y.L., Dai, H.F., Ni, M.J., Cen, K.F., 2008. Characteristic of polychlorinated dibenzo-p-dioxins and dibenzofurans in fly ash from incinerators in China. J. Hazard. Mater. 150, 510-514.

Chi, K.H., Chang, S.H., Chang, M.B., 2008. Reduction of dioxin-like compound emissions from a Waelz plant with adsorbent injection and a dual baghouse filter system. Environ. Sci. Technol. 42, 2111-2117.

Cobo, M., Galvez, A., Conesa, J.A., de Correa, C.M., 2009. Characterization of fly ash from a hazardous waste incinerator in Medellin, Colombia. J. Hazard. Mater. $168,1223-1232$.

Fiedler, H., 2007. National PCDD/PCDF release inventories under the Stockholm Convention on persistent organic pollutants. Chemosphere 67, S96-S108.

Fiedler, H., Lau, C., Eduljee, G., 2000. Statistical analysis of patterns of PCDDs and PCDFs in stack emission samples and identification of a marker congener. Waste Manage. Res. 18, 283-292.

Gao, H.C., Ni, Y.W., Zhang, H.J., Zhao, L., Zhang, N., Zhang, X.P., Zhang, Q., Chen, J.P., 2009. Stack gas emissions of PCDD/Fs from hospital waste incinerators in China. Chemosphere 77, 634-639.

Grochowalski, A., Lassen, C., Holtzer, M., Sadowski, M., Hudyma, T., 2007. Determination of PCDDs, PCDFs, PCBs and HCB emissions from the metallurgical sector in Poland. Environ. Sci. Pollut. Res. 14, 326-332.

Gullett, B.K., Wikström, E., 2000. Mono- to tri-chlorinated dibenzodioxin (CDD) and dibenzofuran (CDF) congeners/homologues as indicators of CDD and CDF emissions from municipal waste and waste/coal combustion. Chemosphere 40, 1015-1019.

Gullett, B.K., Touati, A., Lee, C.W., 2000. Formation of chlorinated dioxins and furans in a hazardous-waste-firing industrial boiler. Environ. Sci. Technol. 34, 20692074.

Holt, E., Weber, R., Stevenson, G., Gaus, C., 2010. Polychlorinated dibenzo-p-dioxins and dibenzofurans (PCDD/Fs) impurities in pesticides: a neglected source of contemporary relevance. Environ. Sci. Technol. 44, 5409-5415.

Jansson, S., Andersson, P.L., 2012. Relationships between congener distribution patterns of PCDDs, PCDFs, PCNs, PCBs, PCBzs and PCPhs formed during flue gas cooling. Sci. Total Environ. 416, 269-275.

Liu, G.R., Zheng, M.H., Liu, W.B., Wang, C.Z., Zhang, B., Gao, L.R., Su, G.J., Xiao, K., Lv, P. 2009. Atmospheric emission of PCDD/Fs, PCBs, hexachlorobenzene, and pentachlorobenzene from the coking industry. Environ. Sci. Technol. 43, 91969201.

Liu, G.R., Zheng, M.H., Lv, P., Liu, W.B., Wang, C.Z, Zhang, B., Xiao, K., 2010. Estimation and characterization of polychlorinated naphthalene emission from coking industries. Environ. Sci. Technol. 44, 8156-8161.

Liu, G.R., Zheng, M.H., Du, B., Nie, Z.Q., Zhang, B., Liu, W.B., Li, C., Hu, J.C., 2012. Atmospheric emission of polychlorinated naphthalenes from iron ore sintering processes. Chemosphere 89, 467-472.

Liu, G.R., Liu, W.B., Cai, Z.W., Zheng, M.H., 2013. Concentrations, profiles, and emission factors of unintentionally produced persistent organic pollutants in fly ash from coking processes. J. Hazard. Mater. 261, 421-426.

Liu, G.R., Cai, Z.W., Zheng, M.H., 2014. Sources of unintentionally produced polychlorinated naphthalenes. Chemosphere 94, 1-12.

Lv, P., Zheng, M.H., Liu, G.R., Liu, W.B., Xiao, K., 2011a. Estimation and characterization of PCDD/Fs and dioxin-like PCBs from Chinese iron foundries. Chemosphere 82, 759-763.

Lv, P., Zheng, M.H., Liu, W.B., Zhang, B., Liu, G.R., Su, G.J., Nie, Z.O., 2011b. Estimation of emissions of polychlorinated dibenzo-p-dioxins and dibenzofurans and dioxin-like polychlorinated biphenyls from Chinese hot dip galvanizing industries. Environ. Eng. Sci. 28, 671-676.

Ni, Y.W., Zhang, H.J., Fan, S., Zhang, X.P., Zhang, Q., Chen, J.P., 2009. Emissions of $\mathrm{PCDD} / \mathrm{Fs}$ from municipal solid waste incinerators in China. Chemosphere 75, 1153-1158. 
74

G. Liu et al./Chemosphere 133 (2015) 68-74

Nie, Z.Q., Zheng, M.H., Liu, W.B., Zhang, B., Liu, G.R., Su, G.J., Lv, P., Xiao, K., 2011. Estimation and characterization of PCDD/Fs, dl-PCBs, PCNs, $\mathrm{HxCBz}$ and PeCBz emissions from magnesium metallurgy facilities in China. Chemosphere 85 , 1707-1712.

Nie, Z.Q., Liu, G.R., Liu, W.B., Zhang, B., Zheng, M.H., 2012a. Characterization and quantification of unintentional POP emissions from primary and secondary copper metallurgical processes in China. Atmos. Environ. 57, 109-115.

Nie, Z.Q., Zheng, M.H., Liu, G.R., Liu, W.B., Lv, P., Zhang, B., Su, G.J., Gao, L.R., Xiao, K., 2012b. A preliminary investigation of unintentional POP emissions from thermal wire reclamation at industrial scrap metal recycling parks in China. J. Hazard. Mater. 215, 259-265.

Oh, J.E., Touati, A., Gullett, B.K., Mulholland, J.A., 2004. PCDD/F TEQ indicators and their mechanistic implications. Environ. Sci. Technol. 38, 4694-4700.

Pandelova, M., Lenoir, D., Schramm, K.W., 2006. Correlation between PCDD/F, PCB and $\mathrm{PCBz}$ in coal/waste combustion. Influence of various inhibitors. Chemosphere 62, 1196-1205.

Richter, S., Steinhauser, K.G., 2003. BAT and BEP as instruments for reducing emissions of unintentionally produced POPs and development of guidelines under the Stockholm Convention. Environ. Sci. Pollut. Res. 10, 265-270.

Takasuga, T., Makino, T., Tsubota, K., Takeda, N., 2000. Formation of dioxins (PCDDs) PCDFs) by dioxin-free fly ash as a catalyst and relation with several chlorinesources. Chemosphere 40, 1003-1007.
Tsuruga, S., Suzuki, T., Takatsudo, Y., Seki, K., Takatsudo, Y., Seki, K., Yamuchi, S., Kuribayashi, S., Morii, S., 2007. On-line monitoring system of P5CDF homologues in waste incineration plants using VUV-SPI-IT-TOFMS. Environ. Sci. Technol. 41, 3684-3688.

Tuppurainen, K., Halonen, I., Ruokojarvi, P., Tarhanen, J., Ruuskanen, J., 1998. Formation of PCDDs and PCDFs in municipal waste incineration and its inhibition mechanisms: a review. Chemosphere 36, 1493-1511.

Tuppurainen, K., Asikainen, A., Ruokojarvi, P., Ruuskanen, J., 2003. Perspectives on the formation of polychlorinated dibenzo-p-dioxins and dibenzofurans during municipal solid waste (MSW) incineration and other combustion processes. Acc. Chem. Res. 36, 652-658.

UNEP, 2014. Stockholm Convention on Persistent Organic Pollutants; <http://www. pops.int/>.

Weber, R., Gaus, C., Tysklind, M., Johnston, P., Forter, M., Hollert, H., Heinisch, E., Holoubek, I., Lloyd-Smith, M., Masunaga, S., Moccarelli, P., Santillo, D., Seike, N., Symons, R., Torres, J.P.M., Verta, M., Varbelow, G., Vijgen, J., Watson, A., Costner, P., Woelz, J., Wycisk, P., Zennegg, M., 2008. Dioxin- and POP-contaminated sitescontemporary and future relevance and challenges. Environ. Sci. Pollut. Res. 15, 363-393.

Yu, B.W., Jin, G.Z., Moon, Y.H., Kim, M.K., Kyoung, J.D., Chang, Y.S., 2006. Emission of $\mathrm{PCDD} / \mathrm{Fs}$ and dioxin-like PCBs from metallurgy industries in S. Korea. Chemosphere 62, 494-501. 